\title{
Território e Subjetividade: narrativas de jovens em uma remoção urbana ${ }^{\star}$
}

\author{
Christiane Silveira Kammsetzer, ${ }^{I, \star \star}$ Analice de Lima Palombini ${ }^{I I}$ \\ ${ }^{I}$ Grupo Hospitalar Conceição, Porto Alegre, RS, Brasil \\ ${ }^{\text {II } U n i v e r s i d a d e ~ F e d e r a l ~ d o ~ R i o ~ G r a n d e ~ d o ~ S u l, ~ R i o ~ G r a n d e ~ d o ~ S u l, ~ R S, ~ B r a s i l ~}$
}

\begin{abstract}
Resumo
Discutiremos neste artigo a relação entre juventude e território, contrapondo o espaço ocupado ao ideal de cidade e subjetividade contido nas remoções urbanas. O artigo é desdobramento da pesquisa "Territórios em movimento: narrativas de jovens sobre viver, habitar, resistir", realizada no mestrado acadêmico do Programa de Pós-Graduação em Psicologia Social da Universidade Federal do Rio Grande do Sul (UFRGS). A pesquisa acompanhou um projeto de extensão universitária realizado em parceria com equipe de atenção primária em saúde de uma comunidade de Porto Alegre em processo de remoção e reassentamento associado às reformas para sediar a Copa do Mundo de 2014. Utilizando-se de narrativas, a pesquisa problematizou a influência das experiências de jovens com os territórios de moradia em sua subjetivação. Os principais orientadores metodológicos foram o Método da Montagem, Narração, Flânerie, de Walter Benjamin. Solidariedade, vizinhança, violência, meio ambiente, rede intersetorial, relação com a cidade foram temas que emergiram.
\end{abstract}

Palavras-chave: subjetividade; território; juventude; remoções urbanas.

\section{Territory and subjectivity: youth's narratives in the urban resettlement}

\begin{abstract}
This article discusses the importance of the territory in the juvenile experiences, especially in urban occupations and in resettlement process, in counterpoint to the ideal of the city and subjectivity in the removals. Results of the research "Moving territories: youth narratives about living, reside, resist”, held in Post Graduate Program in Social Psychology (Master) at the Federal University of Rio Grande do Sul (UFRGS). This study gathered data from a university extension project in partnership with a Primary Care Health Service in a community in an urban resettlement process associated to the 2014 World Cup in Porto Alegre, Brazil. The participants narrated their experiences with their territories and the research questioned the influences of these experiences in their subjectivity. The main methodological references are the Literaly Montage method, Narration, Flânerie, of Walter Benjamin. Solidarity, neighborhood, violence, environment, intersectional network, interaction between them and their city were themes that emerged.
\end{abstract}

Keywords: subjectivity; territory; teenagers; urban resettlement.

\section{Introdução}

A ocupação do espaço urbano em busca de um lugar em que a vida seja possível sempre foi uma realidade nas grandes cidades brasileiras, bem como o movimento de empurrar as populações que ocupam este espaço para regiões periféricas. No entanto, recentemente vimos um movimento das metrópoles em direção à maior mercantilização do espaço urbano, tornando-se as cidades "marcas", “empresas", em ocasião dos megaeventos internacionais. Nesse contexto, a rede de interesses econômicos locais passa a ser camuflada sob o enunciado "interesse da cidade" (ASSUMPÇÃO; FRANCO, 2013). Porto Alegre, capital do Estado do Rio Grande do Sul, foi cidade-sede da Copa do Mundo de 2014. Sob o pretexto da reurbanização e melhoria do espaço urbano, muitas comunidades $^{1}$ consideradas áreas de ocupação foram expropriadas de seus lugares, sendo removidas para regiões distantes do centro urbano. Esta reurbanização não resolveu a questão dos fluxos urbanos nesta e em outras

\footnotetext{
$\star$ Estudo realizado com financiamento próprio.

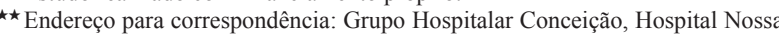
Senhora da Conceição - Gerência de Saúde Comunitária. Av. Francisco Trein, 596 - Setor: Unidade de Saúde Santíssima Trindade - Cristo Redentor - Porto Alegre, RS - Brasil. CEP: 91350200.E-mail: christianekami@gmail.com, analice.palombini@gmail.com

O termo "comunidade" será utilizado aqui quando nos referirmos ao conjunto de pessoas que residem nos territórios de que trata o artigo. A escolha deu-se somente pela facilidade de seu uso. De fato, este termo não expressa a heterogeneidade dos modos de viver e se relacionar nos territórios em que se deu a pesquisa.
}

cidades brasileiras; ao contrário, as reformas urbanas têm se tornado realidade permanente. Em uma associação perversa entre Estado e mercado, ao direito à cidade tem sido sobreposto o interesse econômico por meio da exploração imobiliária (SILVA, 2013).

As experiências urbanas compõem os processos de subjetivação e, em contextos de ocupação, forjar um lugar para viver é construir possibilidades de vida, entendendo subjetividade como "produção sócio-histórica dotada de poder operatório sobre a realidade" (ASSUMPÇÃO; FRANCO, 2013, p. 146). O presente artigo é um desdobramento da pesquisa "Territórios em movimento: narrativas de jovens sobre viver, habitar, resistir", realizada no âmbito do mestrado acadêmico do Programa de Pós-Graduação em Psicologia Social, na Universidade Federal do Rio Grande do Sul (UFRGS), entre 2012 e 2014. A pesquisa teve por objetivo problematizar a importância das experiências urbanas na construção dos territórios existenciais juvenis, refletindo sobre como o lugar onde o jovem vive pode ser uma "referência espacial e afetiva" na produção de suas vidas (CORDEIRO, 2009, p. 215). Com esse intuito, acompanhou jovens que passaram por processo de reassentamento urbano de sua comunidade de origem, relacionado ao megaevento Copa do Mundo - a remoção e o consequente reassentamento da população tiveram como mote a ampliação da pista do aeroporto inter- 
nacional, obra que, passados oito anos, não foi realizada. Em contextos de remoção, o poder público desconsidera as táticas construídas pelos moradores de pertencimento ao lugar de origem, desqualificando a história e a memória da comunidade. Mesmo em remoções não forçadas, os efeitos disso são devastadores, especialmente para os jovens, que estão em momento fecundo de construção de suas vidas (RASSIAL, 1997). Discutiremos neste artigo a juventude na relação com o território, os processos de subjetivação dos jovens que acompanhamos na pesquisa no encontro com o espaço urbano ocupado e com o processo de remoção, buscando afirmar a importância do lugar que se constrói nestes contextos, em contraponto ao ideal de cidade e subjetividade contido nas remoções. Voltar-se para as táticas de produção de vida dos jovens em situações de adversidade qualifica o cuidado em saúde na atenção primária e na saúde mental.

A pesquisa dá consequência ao encontro da sua autora, na condição de trabalhadora psicóloga da atenção primária em saúde, com os efeitos da remoção urbana sobre jovens moradores adscritos à Unidade de Saúde (US) em que atua, no município de Porto Alegre- RS. A partir da Reforma Sanitária e da Reforma Psiquiátrica, novos olhares e modos de cuidado configuraram-se no campo da saúde pública brasileira. A Atenção Primária à Saúde (APS) é locus privilegiado dentro do Sistema Único de Saúde (SUS), favorecendo não só o olhar sobre o adoecimento, mas também sobre as condições de produção de vida e de saúde. "Porta de entrada" para o SUS, este nível de atenção tem como premissa garantir o acesso da população a todos os níveis do sistema, por meio da coordenação do cuidado, provendo cuidados em saúde e prevenção em todas as etapas da vida.

A Unidade de Saúde estava localizada na comunidade que foi removida e também passou pelo processo de mudança para a área de reassentamento. Durante esse processo, um projeto de extensão universitária, que tinha por perspectiva a promoção de saúde e a valorização da história e memória da comunidade no contexto da remoção, foi realizado em parceria entre trabalhadores da Unidade de Saúde, moradores da comunidade, professora e bolsistas da Faculdade de Educação - UFRGS. O projeto de extensão configurou-se como plano de produção de dados da pesquisa, à medida que tinha a valorização da história e das táticas da comunidade como ponto em comum. O principal dispositivo do projeto foi também dispositivo da pesquisa: o processo de criação de filme com jovens moradores, em que se acolheu os diferentes olhares sobre o lugar de moradia e vidas construídas nesses contextos.

\section{Sobre a remoção e seus efeitos}

Remoção e reassentamento tiveram início em 2009 e fizeram parte das reformas urbanas da cidade para receber a Copa do Mundo FIFA 2014. Aproximadamente $80 \%$ de uma população composta, em média, por quatro mil moradores, foi deslocada de seu lugar de origem para outra área mais distante do centro da cidade. A comunidade fica localizada entre o aeroporto internacional e região industriária. Segundo dados do último censo do Instituto
Brasileiro de Geografia e Estatística (BRASIL, 2010), cerca de $64 \%$ da população era composta por crianças e jovens. A área foi ocupada pelos primeiros moradores em 1950 e, nas décadas de 1980 e 1990, teve aumento significativo da população, o que coincide com o período de intensa recessão pela qual passava o país e que afetava sensivelmente as regiões rurais. Boa parte dos moradores era oriunda de zonas rurais do extremo norte do Estado do Rio Grande do Sul, onde prevaleciam os descendentes de imigrantes alemães e italianos. Outros habitantes eram provenientes de comunidades populares da capital e região metropolitana. Composta de uma avenida central, em parte asfaltada e em parte de chão batido e becos/ ruelas, ali era possível aos moradores manter características de suas moradias na área rural (criação de animais, pátios grandes com mais de uma casa, vegetação etc.). A maioria da população tinha como meio de subsistência a coleta de material reciclável e o trabalho em serviços gerais nas fábricas e casas do entorno. Era bastante usual a migração - ir e voltar à cidade de origem - e mesmo a troca de moradia dentro da própria comunidade. Após as primeiras ocupações, as pessoas instaladas no local começaram a comercializar os terrenos, motivo pelo qual muitos que os compraram não consideram ter ocupado a área. Os serviços que atendiam exclusivamente os moradores (Unidade de Saúde e escolas) e os espaços comunitários foram resultado de lutas, sobretudo de mulheres, articuladas com apoio de instituições presentes na comunidade, como congregação religiosa e serviço de saúde.

A perspectiva de remoção sempre esteve presente, por ser uma área de ocupação e pelas repetidas vezes em que autoridades públicas a anunciaram ou omitiram-se na realização de investimentos no local por esse motivo. Ainda que a maior parte da população não quisesse sair da comunidade, muitos moradores expressaram, ao longo dos anos, o desejo de ter melhores condições de moradia e saneamento básico. O megaevento Copa do Mundo FIFA e o consequente aporte de recursos foram aceleradores de um processo que em algum momento aconteceria.

Os moradores foram reassentados em um conjunto habitacional construído com recurso do Programa de Aceleração do Crescimento (PAC), do Ministério das Cidades. O processo foi gerenciado pelo Departamento Municipal de Habitação (DEMHAB) até 2016, quando cerca de 200 casas que estavam destinadas para o reassentamento foram ocupadas por pessoas de outras regiões de Porto Alegre e área metropolitana. Atualmente a desocupação dessa área está em disputa judicial e o reassentamento está suspenso até que seja resolvida essa situação. Localizado em um dos extremos da cidade de Porto Alegre, o conjunto habitacional é composto de casas de um ou dois andares (cuja área é de 36 metros quadrados) conjugadas, formando um condomínio horizontal. Nas esquinas ficam localizados os comércios e, no limite entre o território e as outras casas do bairro, estão o centro social, galpão de reciclagem, unidade de saúde, escola de ensino fundamental, escola infantil, praça. 
Em janeiro de 2014, um grupo de moradores se organizou em um movimento para fazer resistência à remoção. Constituíram associação para que pudessem negociar com o poder público com maior legitimidade e também realizaram atos na cidade, articulados a outros movimentos sociais. Em 2016, na última etapa do reassentamento ocorrido até então (após quatro anos em que não houve remoções nem investimentos na área), apenas os moradores que desejavam mudar de área foram realocados. Permaneceram no local de origem aqueles que reivindicam a posse do território e quem ainda não foi contemplado no processo de reassentamento, em condição gravíssima de violação de direitos - com acesso dificultado às políticas de saúde, educação, assistência social e com fornecimento de água, luz e saneamento precários.

As mudanças decorrentes do reassentamento não se restringem à moradia, mas têm impacto nos modos de ser comunidade, de se relacionar com a cidade, com o trabalho, nos estereótipos associados ao imaginário que se produz sobre bairros populares e que distanciam os diferentes atores que compõem o espaço urbano. Movimentam-se os territórios existenciais à medida que se deixa um lugar ocupado e construído a partir de lutas por condições básicas de moradia e cidadania e que, por não ser totalmente regulado pelo Estado, permitia certa liberdade de preservar aspectos de seus costumes e origem rural. Passa-se a habitar um espaço padronizado, predominantemente urbano, protótipo da metrópole.

\section{Considerações sobre a metodologia}

$\mathrm{O}$ estudo de que trata o artigo constituiu-se como uma pesquisa-intervenção, portanto de caráter qualitativo, articulada a um projeto de extensão universitária. Utilizamo-nos de abordagem narrativa a fim de compreender as experiências dos jovens com o espaço urbano, no contexto da remoção. De acordo com Onocko-Campos et. al (2013), em pesquisas qualitativas no campo da saúde coletiva temos a necessidade de usar abordagens que se aproximem da complexidade dos objetos de estudo, que considerem seus diferentes contextos e momentos históricos. Desse ponto de vista, não há uma única técnica narrativa apropriada, devemos buscar aquela que esteja de acordo com o problema em questão. Ao discorrer sobre ativismo em pesquisa no contexto dos megaeventos na cidade do Rio de Janeiro, Assumpção e Franco (2013, p. 151) afirmam que "enquanto uma cidade hegemônica se ergue, uma cidade menor vaza". Afirmam a resistência como criação e a pesquisa como um modo de acompanhar os traços de vida que os grupos sociais desenham no espaço urbano. O pesquisador é apoio em um processo de construção de si e de cidades menores. Aproximamo-nos de Walter Benjamin e de seus estudos sobre a urbanidade para construir uma metodologia implicada com o processo de pesquisa aqui descrito. Tomamos como referência alguns temas trabalhados pelo filósofo: "narração", "método da montagem", "flânerie".

A “narração", como veículo da experiência, tem aproximação com a proposta metodológica da pesquisa, em que operamos com as narrativas dos jovens. No ensaio
"O Narrador: considerações sobre a obra de Nikolai Leskov" (BENJAMIN, 1994a), o filósofo escreve sobre a transmissão das experiências e saberes ligados às narrativas. Tais experiências não pertencem a um indivíduo e sim são histórias cuja autoria nem sempre é determinada, mas que se relacionam com situações experienciadas por pessoas, coletivos. Muitas vezes são histórias já contadas e que são recontadas; conforme o autor, "contar histórias sempre foi a arte de contá-las de novo e ela se perde quando as histórias não são mais conservadas" (BENJAMIN, 1994a, p. 205). Inspirado em Nietzsche, Benjamin compreendia que o historiador - aqui o pesquisador -, para além de restaurar, deveria "nadar contra as ondas da história" (NIETZSCHE apud LOWY, 2005, p. 73), isto é, como cronista da história, deveria fazer contraponto à história oficial - esta que é construída desde a perspectiva dos "vencedores", daqueles que estão em posição de dominação -, recusando uma pretensa objetividade e concepção de passado como tempo acabado (FERREIRA, 2012). A "narração" tem, portanto, como perspectiva, a transformação do presente (ONOCKO-CAMPOS et al, 2013). As narrativas possibilitam conhecer outros pontos de vista. Ao mesmo tempo, estão apoiadas na memória e, portanto, sempre a se atualizar e transformar de acordo com as novas experiências que acontecem a todo tempo.

$\mathrm{O}$ "método da montagem" serviu como um guia para que a pesquisa colhesse os "trapos", os "restos", os "cacos", portanto os vestígios de um passado em vias de ser apagado, as narrativas dissonantes e as contradições nos relatos dos jovens. "Nada pode ser posto de lado para a captação viva e fecunda do momento" (BENJAMIN apud MOLDER, 2010, p. 31). Apresentar o detalhe, destacar aspectos aparentemente secundários, compor, combinar, cruzar, seriam modos de entrar em contato com os sentidos partilhados pelos homens em outros tempos (PESAVENTO, 2004). Os "cacos da história", termo usado por Benjamin, são sinais, "sintomas" (PESAVENTO, 2004, p. 64), condensação de sentidos que revelam a mentalidade e sensibilidades de uma época. "Pedaços de histórias incompletas, fragmentos de narrativas seriam montados pelas urgências políticas do agora" (BAPTISTA, 2008, p. 3).

O flâneur é um personagem literário, um tipo que remete a um modo de ser típico da Paris do século XIX. O "ocioso sonhador", representante da mentalidade pequeno-burguesa (BOLLE, 1994) que caminha pela cidade sem pressa, sob as luzes e sombras dos lampiões a gás, observando pessoas e acontecimentos. É cronista e poeta das galerias, espaços intermediários entre a rua e o interior da casa (BOLLE, 1994). As reformas urbanas que aconteceram em Paris no século XIX, imprimindo o traço da Modernidade em uma cidade que tinha características medievais, ampliaram a sensação de pertencimento e proteção dos cidadãos para que pudessem circular - e comprar- livremente pelo espaço urbano, longe de qualquer perigo. No entanto, logo a cidade passou a atrair uma grande quantidade de pessoas, uma "multidão" que colocou o flâneur entre o espaço público (rua) e o espaço privado (casa), o anonimato e o protagonismo, o 
sonho e a realidade. Eis a metrópole que encontramos no nosso tempo, forjando encontros e desencontros, produzindo invisibilidades, "indiferença brutal, isolamento insensível de cada indivíduo em seus interesses privados" (BENJAMIN, 1994b, p. 54). Como pesquisar as experiências dos jovens em seu território, bairro, cidade e as táticas de resistência às subjetividades hegemônicas, bem como a inventividade construída a partir destas experiências? Recuperamos o flâneur no que ele pode inspirar a ética do pesquisador em um modo de fazer pesquisa "andarilho", compromissado com uma crítica da cultura (BOLLE, 1994). "A figura multifacetada do flâneur é usada como instrumento de percepção e mapeamento da paisagem social" (BOLLE, 1994, p. 21) e nos ajuda a desacelerar em um tempo de aceleração, a nos aproximarmos do plano de pesquisa de um jeito mais suave, considerando sua complexidade e contradições.

Ao estudarmos a experiência urbana na cidade contemporânea, não devemos buscar uma "excepcionalidade" em nossa época nem causalidades artificiais entre o tempo atual e o passado, mas, sim, estarmos atentos para perceber o que do presente remete às sensibilidades do passado (FERREIRA, 2012). A cidade apresenta indícios da narratividade hegemônica, mas, também, do que lhe escapa, das práticas dissonantes, das resistências.

Walter Benjamin sugere a investigação histórica a partir do inacabamento da subjetividade, refeita precariamente de acordo com a lembrança e o esquecimento, a infância e a experiência, o desejo e a perda da suposta linearidade e completude de narrativas. Pesquisam-se as cidades para que se possa entender a história silenciosa que é inscrita nas coisas. Para Benjamin, é como se tratasse de reivindicar uma suspensão da história teleológica a fim de alcançar uma visibilidade profana de camadas de acontecimentos que ainda não foram reconhecidos (FERREIRA, 2012, p. 167).

Escutar as narrativas dos jovens buscando acolher a singularidade da experiência de cada um, sem buscar generalizações ou leituras identitárias, foi um cuidado metodológico e ético. Foi fundamental, neste percurso, a reflexão constante sobre a dimensão política envolvida (política como construção de modos de existência) e, em função disso, a constante análise de implicação, isto é, a "análise do impacto que as cenas vividas e observadas têm sobre a história do pesquisador e sobre o sistema de poder que legitima o instituído, incluindo aí o próprio lugar de saber e o estatuto de poder do pesquisador" (PAULON, 2005, p. 23). Conforme alerta Cordeiro (2009, p. 76),

A escrita está intimamente associada ao poder (GNERRE, 1998). Esse debate conduz também à reflexão acerca da possibilidade de produzirmos uma escrita menos violenta, em que o sujeito pesquisado não é exatamente o 'bom nativo', isto é, absolutizável, mas que nos permita enxergar uma cisão, orientalizando o olhar.

A pesquisa acompanhou os jovens nos espaços e atividades propostas pelo projeto de extensão ao longo de 2013. Os procedimentos metodológicos foram a criação de dispositivos que possibilitassem a emergência de narrativas dos jovens sobre suas experiências urbanas, em especial em relação aos lugares de moradia (de origem e reassentamento) e ao processo de remoção. Tais dispositivos (da pesquisa e do projeto de extensão) foram rodas de conversa, oficinas de cinema e filmagens. $O$ registro foi feito em diário de campo. Além disso, fizeram parte do estudo as memórias da pesquisadora: narrativas recolhidas em diários em momentos diversos da experiência com os jovens no cotidiano de trabalho na Unidade de Saúde. Também foram utilizados materiais do projeto de extensão (transcrição de entrevistas e rodas de conversa) com autorização da coordenadora do projeto.

Muitos foram os jovens que passaram pela oficina de cinema, porém quatro permaneceram por mais tempo, permitindo-nos conhecer melhor suas experiências. À medida que o grupo ia se formando, ideias e imagens começavam a ser compartilhadas e ganhavam ou perdiam força ao entrar no comum do grupo. O roteiro do filme, proposto por eles, consistia em mostrar um dia de vida de amigos que estudam na mesma escola, porém que residem em locais diferentes. Neste dia, transitaram por ambos os territórios - o original e o do reassentamento. A pesquisa não pôde acompanhar o processo de construção do filme até o final, pois o mesmo foi concluído em 2015, um ano após a conclusão do mestrado acadêmico. O roteiro foi revisado no último ano de trabalho, e as memórias dos jovens envolvidos no projeto entraram no lugar das imagens que seriam filmadas na comunidade de origem, o que parece refletir o movimento próprio da mudança, que vai trazendo, à medida que o tempo passa, outras perspectivas em relação ao lugar onde não se vive mais.

As narrativas produzidas no processo da pesquisa traduzem a multiplicidade de experiências dos jovens com seus territórios de moradia. A permanência destes sentidos depende de um jogo complexo de forças (políticas, econômicas, sociais, subjetivas) sendo este percurso singular e datado, já que o tempo presente reconstrói a todo instante a memória e a história.

\section{Jovens e experiências urbanas: narrativas em contexto de remoção}

Os agrupamentos juvenis expressam as multiplicidades culturais de suas localidades e a "diversidade interna das sociedades em que vivem em termos de ethos, estilos de vida, visões de mundo e, em geral, modos de construção social da realidade" (VELHO, 2006, p. 192). Assim,

Os jovens na sociedade não constituem uma classe social, ou grupo homogêneo como muitas análises pretendem intuir. Os jovens compõem agregados sociais com características continuamente flutuantes. As idealizações políticas que procuram unificar os sentidos dos movimentos sociais da juventude tendem a ser ultrapassadas pelo contínuo movimento da realidade (CARRANO, 2003, p. 110).

Trata-se de conhecer o modo como "fabricam e reconhecem os seus particulares modos de vida, suas identidades e relações de pertença" (PAIS, 1999, p. 11), visibilizar as condições ou determinantes sociais de jovens que vivem em contextos de vida singulares: 
Traços de vida que matizam cotidianos juvenis, grafias dançantes de significados de vida em sua errância semântica. Um traço instaura (por inclusão) um lugar de escrita - a vida que se escreve, inscreve e descreve - lugar de execução e gestão de desejos e vontades, ansiedades e frustrações, expectativas e desilusões. Gestão de gestos, gestos de vida, tocados e retocados, preenchendo modos ou quadros de vida. Traços de vida que a ajudam a moldar, combinando diferentes estilos e usos, acentuando singularidades, estabelecendo códigos. Traços de vida que, eventualmente, projetam riscos de vida (PAIS, 1999, p. 10).

A diversidade das experiências dos jovens tem relação com a própria diversidade social que constitui os lugares. Tornar-se jovem na cidade é um processo que, mesmo tendo como referências as grandes linhas de produção de subjetividade globais (estéticas que se apresentam para os jovens urbanos), ganha contornos específicos a partir das experiências vividas em suas redes de sociabilidade locais (NETO, 2010). As relações estabelecidas nos lugares definem o modo como serão apreendidas as leis, valores e normas colocadas no social. Na experiência singular, no cotidiano, agem a criatividade e a pluralidade de táticas (CERTEAU, 2013).

Ao narrarem sobre as experiências na comunidade de origem, os jovens pontuaram alguns modos de se relacionar como característicos do lugar, das pessoas que nele habitavam, como uma "tradição" local. O senso de coletividade e as ações dos moradores pró-comunidade produziam sensação de pertencimento e identificação, aspecto marcante da vida vivida naquele lugar. A articulação comunitária no enfrentamento de situações que afetavam a todos era compreendida como expressão desta vida comunitária. Tais situações relacionavam-se à precariedade das condições sanitárias, falta de luz, buracos na via de acesso, falta de água, violência policial. As condições socioambientais do território de origem traziam dificuldades, porém, o modo como se lidava com isso parecia ser no sentido de tornar mais leve o cotidiano pesado de adversidades. O mesmo barro, que, segundo os jovens, atrapalhava a circulação em dias de chuva, também é descrito como um fator a mais na paisagem, até com um caráter lúdico. Em diversos momentos escutamos narrativas que valorizavam o contato com a natureza no antigo lugar. Lembranças das árvores frutíferas no pátio de casa, dos animais - cavalos, porcos, galinhas, cachorros, gatos. Para o lugar novo, puderam levar apenas os de estimação. Como forma de enfrentamento de situações mais extremas, os moradores acionavam os setores públicos e, quando não eram contemplados em suas reivindicações, mobilizavam manifestações e protestos, com fechamento da avenida principal, construção de "barricadas" (queima de pneus interditando a via), a fim de dar visibilidade para as situações sofridas. Esta articulação em muito era possível pelas relações de vizinhança estabelecidas e também pela liderança que alguns moradores foram assumindo. Segundo a fala de uma jovem, havia "união pra fazer as coisas". A união e a solidariedade eram aspectos positivos reconhecidos pelos jovens. Conhecer os vizinhos, ter vários amigos de longos anos eram aspectos considerados positivos e favoreciam a articulação comunitária necessária em muitos momentos. Com a remoção, as relações de vizinhança se modificaram, uma vez que o projeto urbanístico do novo local não contemplou a distribuição dos moradores nas casas da forma como era anteriormente.

O território em que se vive (bairro, comunidade) é o lugar de passagem por um outro que não é anônimo nem necessariamente íntimo, é vizinho. Desde a infância, experimentar o lugar em que se vive, conviver com os vizinhos, pisar o chão, são práticas que possibilitam o reconhecimento do espaço como social, é a "configuração primeira de todo processo de apropriação do espaço como lugar da vida cotidiana pública" (MAYOL, 2012, p. 44). As lembranças que ficaram para os jovens em relação à comunidade de origem dizem de um lugar pulsante, povoado de acontecimentos e encontros cotidianos. Certeau (2012, p. 45) traz uma reflexão sobre a cidade que se encontra com esta imagem:

A cidade é, no sentido forte, "poetizada" pelo sujeito: este a refabricou para seu uso próprio desmontando as correntes do aparelho urbano; ele impõe à ordem externa da cidade sua lei de consumo do espaço. O bairro é, por conseguinte, no sentido forte do termo, um objeto de consumo do qual se apropria o usuário no modo de privatização do espaço público. Aí se acham reunidas todas as condições para favorecer esse exercício: conhecimento dos lugares, trajetos cotidianos, relações de vizinhança (política), relação com os comerciantes (economia), sentimentos difusos de estar no próprio território (etologia), tudo isso como indícios cuja acumulação e combinação produzem, e mais tarde organizam o dispositivo social e cultural segundo o qual o espaço urbano se torna não somente o objeto de um conhecimento, mas o lugar de um reconhecimento (grifo do autor).

As histórias compartilhadas, as memórias dos moradores mais antigos, que vão passando de geração em geração através da oralidade, são vetores que legitimam sentimentos de identificação com o lugar em que moram. Os jovens criaram um "apelido" que faz referência ao nome do antigo local de moradia e também muitos usam uma marca gráfica nos espaços em que circulam atualmente. Esta marca, que inicialmente representava determinado grupo dentro da comunidade, passou a ser ícone de boa parte dos jovens, um jeito de se apresentar, de dizer de onde vêm, quem são. Funciona, assim, como vetor de existencialização (PELBART, 2003), tática de pertencimento que dava suporte aos territórios existenciais construídos diante do movimento veloz de desterritorialização que o momento histórico produzia. Aparecia em suas falas uma sensação de continuidade entre o lugar em que viviam e o lugar para onde foram reassentados, em que a comunidade de origem ainda é referência (tanto positiva quanto negativa). Com a mudança de lugar, movem-se os territórios existenciais, que são assinaturas, modos de se apresentar (mais do que se representar) que se mantêm no tempo (DELEUZE; GUATTARI, 1997). São as marcas produzidas no movimento de tornar-se, na territorialização, os quais não estão dados a priori. A assinatura não indica uma pessoa e sim um domínio, 
uma morada, uma tomada de lugar. Ao mesmo tempo, os territórios sempre portam coeficientes de desterritorialização, não são estáticos. No reassentamento, mais do que os espaços de moradia, também a subjetividade se transforma, uma vez que é indissociável das relações em que está inserida e que produz. Os processos de subjetivação investem as relações consigo e com os outros no mesmo movimento, são experimentações de modos de vida compartilhados, de produção de comum (REVEL, 2012). No contexto do reassentamento, esses processos ganharam novos vetores, mas mantiveram alguns que já possuíam, como pudemos constatar a partir das narrativas.

Para além do processo vivido por estes jovens, se pensarmos na produção de vida e de sujeitos que se dá nos espaços ocupados desta e de outras cidades, entendemos que estes vetores de existencialização precisam ser conhecidos e compreendidos pelas pessoas que trabalham junto às populações destes territórios. Quando se desconhece estas realidades e a potência das táticas utilizadas nestes contextos, é comum a tentativa de captura dos jovens por práticas regularizadoras de comportamentos e valores nos espaços instituídos em que circulam - escola, unidade de saúde, assistência social, entre outros - o que dificulta, por vezes, seus processos de singularização para além dos comportamentos "prescritos" (CORDEIRO, 2009).

As atividades culturais criadas pelos próprios jovens e outros atores sociais na comunidade de origem, que aconteciam nos pátios das casas e espaços comuns, também foram narradas no processo de pesquisa. Todos os jovens que participavam destas atividades destacam que, com a remoção, perderam espaço para realizá-las em função da disposição das moradias. Os grupos que protagonizavam tais ações eram reconhecidos pelos moradores, contribuíam com o "espírito" da comunidade, eram parte da geografia, da paisagem cultural daquela população. Dois jovens que estiveram em momentos diferentes do projeto contam que foram oficineiros de atividades culturais, uma realizada dentro do território (grupo de dança infantil) e outra na escola local (capoeira). Sentiam-se bem cuidando e educando outras crianças e jovens que também pertenciam à comunidade. Aquele que realizava atividade de oficina na escola acredita que tal ação contribuía para que os jovens trilhassem um caminho diferente do crime e do uso abusivo de substâncias psicoativas, para que encontrassem outras alternativas de vida para além desta realidade. Era uma ação que, além de transmitir conhecimento, propiciava o diálogo. Quando teve fim, segundo o jovem, houve vários amigos e educandos que "se perderam". Percebemos que o que dava sustentação a estas práticas emancipatórias, desde o ponto de vista dos jovens, era o interesse e o envolvimento das pessoas - sejam elas da comunidade ou não - mais do que a política dos serviços que atendem a esta população.

A violência estava presente no cotidiano no lugar de origem e intensificou-se na área de reassentamento. Segundo os jovens, a comunidade em que viviam era vista como um lugar "de lazer", mas também de "bagunça", o que remete aos conflitos envolvendo seus moradores e pessoas de outras regiões da cidade, especialmente uma comunidade que ficava próxima e com a qual havia uma rivalidade ao longo do tempo. Segundo um dos jovens, no centro da cidade os moradores da comunidade eram conhecidos pelas brigas em que se envolviam nas festas/ bares/sons. Por esse motivo, ser morador daquele lugar de certa forma os "protegia" em seus percursos já que, dada a "fama", era mais difícil que "mexessem" com eles (segundo relato de jovens no contexto de realização de atividade da Unidade de Saúde em 2009, registrada em diário pela pesquisadora). No novo local, os jovens contam que ocorrem tiroteios em diferentes momentos do dia, sem que se saiba quando, diferente da comunidade de origem, em que muitas vezes os moradores eram avisados sobre momentos mais críticos, o que parecia gerar sentimento de maior segurança. Outra questão que aparece nas falas é a proteção dos familiares em relação aos jovens diante de um cenário de risco para a violência. Preferem que fiquem dentro da casa e do pátio. Há também receio, por parte dos jovens e de seus familiares, quanto ao envolvimento com grupos que usam e comercializam drogas "nas esquinas". Se, por um lado, isso traz uma limitação para a liberdade de circulação (comparado ao local anterior), por outro, fica claro o cuidado que está contido nesta restrição de alguns dos jovens ao espaço da casa em alguns momentos do dia. Diz uma jovem:

Não existe um lugar que não tenha aquela violência ou aquela coisa. Eu acho que, com tantas diferenças, tem um pouco de igualdade nisso. Até porque todo mundo mora naquele lugar. Se ele faz aquilo, é porque ele precisa ou porque ele tem algum problema ou sei lá. E tem pessoas que lutam porque são pessoas na mesma... que moram todo mundo ali (entrevista realizada no âmbito do projeto de extensão).

A condescendência com o tráfico de drogas expressa nessa fala não é incomum entre os moradores, talvez por certa ilusão identitária de que todos ali compartilham da mesma vivência, na medida em que o que os leva a viver naquele lugar é a necessidade. Pode indicar, também, um reconhecimento de classe, em oposição a outras classes com maior poder aquisitivo, e nesse ponto expressar resistência, porém sem refletir sobre a manutenção da condição de segregação pela via do crime/violência.

A territorialidade é resultado de práticas sociais cotidianas envolvendo os indivíduos que habitam os territórios e as instituições; ambos imprimem relações de poder sobre o espaço (HEIDRICH, 2010). O território ocupado não era desenhado apenas pelos moradores, mas também pelas instituições que ali se faziam presentes direta ou indiretamente, atendendo a necessidades da população e também prerrogativas do Estado. Estava intrinsecamente relacionado ao entorno e à cidade. Os jovens destacam, em suas narrativas, o lugar das escolas em seus percursos, em especial a que atende somente a população da comunidade de origem e a primeira que recebeu os alunos que mudaram de território. São vistas como espaços de inclusão ou exclusão, dependendo da acolhida que conseguem dar às necessidades de seus alunos. Percebemos a importância que atribuem aos laços estabelecidos com os professores e também com os outros trabalhadores envolvidos nos espaços que frequentam. Os jovens que 
mudaram de escola destacaram como positiva a possibilidade de fazer novas amizades e, como negativa, a falta de infraestrutura adequada em algumas escolas da região, que atendem um grupo muito grande de alunos. Em relação à cidade, é referida a distância do centro e dos lugares que eles costumavam frequentar - dizem que o lugar onde hoje moram é "longe de tudo". Porém, alguns jovens afirmam ter ampliado suas saídas pela cidade após a mudança, o que supomos estar mais relacionado à idade (e à permissão dos familiares de que saiam) do que à localização do novo território. Alguns jovens que continuaram estudando na escola anterior precisavam se deslocar de ônibus, trajeto que acompanhamos nas primeiras filmagens. Percebemos que muitos ainda tinham como referência os equipamentos sociais que utilizavam, o que pode ser do processo de se habituar a um novo lugar, mas, também, pode ser visto como uma tática tomada diante da dificuldade de inserção plena no novo bairro (por falta de vaga na escola da região, por dificuldade de acesso às políticas de assistência social e de esportes). Uma questão que emergiu no processo foi o modo como os jovens nomeiam as atividades propostas a eles - como "oportunidades" -, o que leva a alguns possíveis entendimentos. Pode indicar uma percepção de que, para estarem na condição plena de cidadania, seria preciso um esforço pessoal, "agarrar a oportunidade", reproduzindo uma visão comum no imaginário social, que atribui ao indivíduo a superação da condição socioeconômica, e não ao conjunto das políticas públicas. Por outro lado, do ponto de vista dos jovens, talvez reflita uma realidade vista e experimentada em seu cotidiano. Diversas ações eram promovidas, tanto por lideranças comunitárias como pelos serviços que atendiam a população.

Os discursos que nomeiam os moradores de regiões empobrecidas da cidade, seja desde um viés conservador ou progressista, acabam por contribuir com visões distorcidas que afetam sensivelmente os jovens (SOUZA E SILVA, 2011). De um lado, superestimam a associação entre pobreza, risco e violência, atribuindo estereótipos aos meninos e aos jovens. Percebemos isso nos muitos encaminhamentos para a Psicologia de meninos entre dez e treze anos de idade, por apresentarem "comportamento agressivo" ou por serem vistos como "lideranças negativas" nos grupos escolares. Rapidamente, as histórias de vida destes meninos vêm coladas a tais comportamentos nos discursos de professores e orientadores educacionais, indicando uma suposta relação de causa e efeito. De outro lado, os discursos progressistas resultam na vitimização ou na compreensão de que as pessoas em situação de pobreza sofreriam passivamente as adversidades. Esta visão pode contribuir para uma "postura paternalista e empobrecedora da cidadania” (SOUZA E SILVA, 2011, p. 217). Preferimos dar visibilidade às "maneiras de fazer" próprias das pessoas que acompanhamos, como intermedeiam ordem social e vida cotidiana, com que repertórios procedem operações próprias nos lugares em que vivem (CERTEAU, 2013, p. 87-88).
A sociedade ainda precisa transformar suas mentalidades, produto de décadas de recessão e despolitização. Acreditamos que há um caminho a se construir nesse sentido. Que a cidade possa acolher a diferença e ser inclusiva. Cidade que é feita de pessoas e seus gestos.

\section{Algumas considerações finais}

O novo lugar que, aparentemente, está mais alinhado a um projeto de cidade e onde, portanto, fica mais visível o traço do Estado em seu desenho, é modificado à medida que a população dele se apropria. De acordo com Certeau (2012, p. 199),

Seu patrimônio [da cidade] não é feito dos objetos que ela criou, mas das capacidades criadoras e do estilo inventivo que articula, à maneira de uma língua falada, a prática sutil e múltipla de um vasto conjunto de coisas manipuladas e personalizadas, reempregadas e "poetizadas". Finalmente, o patrimônio são todas essas "artes de fazer".

Pelo modo como vem acontecendo, sem envolvimento efetivo dos cidadãos, que não são chamados a participar do processo, a remoção da comunidade pode ser entendida como uma situação que implica conflito de interesses entre os indivíduos que ali residiam e as instituições que representam o poder público, especialmente o setor de habitação. O modo como tem se dado trouxe prejuízos para os jovens em um momento peculiar de vida, quando dois, três, oito anos (tempo que já dura o processo) é muito em seus percursos. A oferta de assistência para esse público ficou bastante prejudicada, em função de não ter havido um planejamento preciso quanto ao reassentamento dos serviços públicos que atendem a população. A Unidade de Saúde teve sua obra concluída dois anos e meio após o início da remoção. A escola local iniciou as atividades em 2014. Este descuido trouxe danos para muitos moradores jovens. Atualmente, os moradores que ainda residem na comunidade são os prejudicados, tendo que se deslocar de um bairro a outro para acessar a Unidade de Saúde e outros recursos. Aqueles que se mudaram para lá após a saída da Unidade de Saúde do território e que, portanto, não foram cadastrados, estão sem equipe de referência (apesar da área estar sob a responsabilidade sanitária do distrito em que a comunidade está localizada).

As narrativas dos jovens que aqui traçamos dizem de um desejo de cidadania. De que possam ter um lugar de moradia adequado; que possam acessar atividades culturais e serviços que os acolham e onde expressem seus modos de ser sem críticas ou constrangimentos; que tenham direito à amizade; que tenham direito à memória; que não sejam alvo de olhares que os diminuam ou imprimam estereótipos às suas vivências; que possam circular livremente em seu território de moradia, bairro e cidade. Percebemos que, dentre estes desejos, alguns significam a permanência de conquistas de cidadania que foram possíveis na comunidade de origem. É o passado mobilizando o presente.

Estar em contato com as histórias, com os desejos e receios dos jovens, para além dos padecimentos em saúde mental e dos traços de vulnerabilidade social que alguns carregam, foi algo que trouxe vida para um tra- 
balho tão delicado e ao mesmo tempo tão duro que é o da Psicologia no campo da saúde. Ricardo Moretzsohn, em Seminário sobre Mobilidade Urbana promovido pelo Conselho Federal de Psicologia, tece algumas propostas para a Psicologia no encontro com a cidade:

A Psicologia deve intervir para mapear a cidade, não por seu traçado arquitetônico, mas pelos traços desenhados pelos processos de subjetivação na contemporaneidade. Ela deve questionar a iniquidade do traçado arquitetônico na distribuição dos benefícios e tentar compreender os processos de subjetivação que compõem esse caleidoscópio da mobilidade humana. O seu compromisso é de participar da construção de uma rede social em que caibam diversas formas de subjetivação, produzidas com processos históricos que promovem, silenciosa e violentamente, o massacre da singularidade em favor de interesses dominantes, engessando as diversas possibilidades de expressão, de traçados subjetivos no espaço público, impedindo a mobilidade dos sujeitos, negando a complexidade da circulação humana (CONSELHO FEDERAL DE PSICOLOGIA, 2010, p. 70-71).

Em processos de remoção, a memória coletiva, fio que costura a vida, é o que possibilita as passagens, os movimentos de desterritorialização, sem que se perca no caos. Deve ser valorizada sem ser sacralizada ou suposta identitária. Não há identidade, assim como não há território. Há processos de identificação, de territorialização. Há produção, movimento.

\section{Referências}

ASSUMPÇÃO, E.; FRANCO, T. Por uma cidade menor: hegemonia e resistência na cidade do Rio de Janeiro. Rev. Lugar Comum, n. 39, p. 145-155, 2013.

BAPTISTA, L. Walter Benjamin e os anjos de Copacabana. 2008. Disponível em: <http://www.slab.uff.br/psm/uploads/ texto93.pdf>. Acesso em: 10 jan. 2014.

BENJAMIN, W. O narrador: considerações sobre a obra de Nikolai Leskov. In:__. Magia e técnica, arte e politica: ensaios sobre literatura e história da cultura. São Paulo: Brasiliense, 1994a. p. 197-221. Obras Escolhidas, v. 1.

BENJAMIN, W. Paris do Segundo Império. In: Charles Baudelaire: um lírico no auge do capitalismo. São Paulo: Brasiliense, 1994b. p. 9-101. Obras Escolhidas, v. 3.

BOLLE, W. Fisiognomia da metrópole moderna: representação da História em Walter Benjamin. São Paulo: Edusp, 1994.

BRASIL. Instituto Brasileiro de Geografia e Estatística. Censo Demográfico 2010. Disponível em: <https://ww2.ibge.gov.br/ home/estatistica/populacao/censo2010/default.shtm>. Acesso em: 3 jan. 2014.

CARRANO, P. Juventudes e cidades educadoras. Petrópolis, RJ: Vozes, 2003.

CONSELHO FEDERAL DE PSICOLOGIA. Psicologia $e$ mobilidade: o espaço público como direito de todos. Brasília: CFP, 2010. Disponível em: <http://site.cfp.org.br/publicacao/ psicologia-e-mobilidade-o-espaco-publico-como-direito-detodos>. Acesso em: 10 jan. 2015.

CORDEIRO, D. Juventude nas sombras: escola, trabalho e moradia em territórios de precariedades. Rio de Janeiro: Lamparina/Faperj, 2009.

CERTEAU, M. de. A invenção do cotidiano: morar, cozinhar. Petrópolis, RJ: Vozes, 2012. v. 2.
CERTEAU, M. de. A invenção do cotidiano: artes de fazer. Petrópolis, RJ: Vozes, 2013. v. 1.

DELEUZE, G.; GUATTARI, F. Mil platôs: capitalismo e esquizofrenia. São Paulo: Editora 34, 1997. v. 4.

FERREIRA, M. Walter Benjamin e a cidade. In: BAPTISTA, L. A.; FERREIRA, M. (Org.). Por que a cidade? Escritos sobre experiência urbana e subjetividade. Niterói: Eduff, 2012. p. 153-168.

HEIDRICH, A. Espaço e multiterritorialidade entre territórios: reflexões sobre a abordagem territorial. In: PEREIRA, S. et al. (Org.). Teoria e práticas territoriais: análises espaço-temporais. São Paulo: Expressão Popular, 2010. p. 25-35.

LOWY, M. Walter Benjamin: aviso de incêndio: uma leitura das teses "Sobre o conceito de história". São Paulo: Boitempo, 2005.

MAYOL, P. Morar. In: CERTEAU, M. de. A invenção do cotidiano: morar, cozinhar. Petrópolis, RJ: Vozes, 2012. v. 2, p. 37-207.

MOLDER, M. Método é Desvio: uma experiência de limiar. In: OTTE, G.; SEDLMAYER, S.; CORNELSEN, E. (Org.). Limiares e Passagens em Walter Benjamin. Belo Horizonte: UFMG, 2010. p. 27-75.

NETO, N. Geografia das juventudes: uma pauta de pesquisa. In: PEREIRA, S. et al. (Org.). Teoria e práticas territoriais: análises espaço-temporais. São Paulo: Expressão Popular, 2010. p. 85-97.

ONOCKO-CAMPOS, R. et al. Narrativas no estudo das práticas em saúde mental: contribuições das perspectivas de Paul Ricoeur, Walter Benjamim e da antropologia médica. Ciênc. saúde coletiva, Rio de Janeiro, v. 18, n. 10, p. 28472857, out. 2013. Cross ${ }^{\text {Ref. }}$

PAIS, J. M. Traços e riscos de vida. Porto: Ambar, 1999.

PAULON, S. M. A análise de implicação como ferramenta na pesquisa-intervenção. Psicologia \& Sociedade, Porto Alegre, v. 17, n. 3, p. 18-25, set./dez. 2005. Cross ${ }^{\text {Ref. }}$

PELBART, P. Vida capital: ensaios de biopolítica. São Paulo: Iluminuras, 2003.

PESAVENTO, S. História \& História Cultural. Belo Horizonte: Autêntica, 2004.

RASSIAL, J-J. A passagem adolescente: da família ao laço social. Porto Alegre: Artes e Ofícios, 1997.

REVEL,J.Resistências, subjetividades, ocomum.LugarComum, n. 35-36,p.107-114,2012.Disponívelem <http://uninomade.net/ wp-content/files_mf/110210120912Resist $\%$ C3\%AAncias\%20 subjetividades\%200\%20comum\%20-\%20Judith\%20Revel. pdf>. Acesso em: 24 out. 2014.

SILVA, R. Direito à Cidade. In: XIMENDES, A.; REIS, C.; OLIVEIRA, R. (Org.). Entre garantia de direitos e práticas libertárias. Porto Alegre: Conselho Regional de Psicologia do Rio Grande do Sul, 2013. p. 109-122. Disponível em: $<$ http://crprs.org. br/upload/edicao/arquivo60.pdf $>$. Acesso em: 10 out. 2017.

SOUZA E SILVA, J. Um espaço em busca de seu lugar: as favelas para além dos estereótipos. In: SANTOS, M. et al. Território, territórios: ensaios sobre o ordenamento territorial. Rio de Janeiro: Lamparina, 2011. p. 209-230.

VELHO, G. Juventudes, projetos e trajetórias na sociedade contemporânea. In: ALMEIDA, M. I.; EUGÊNIO, F. (Org.). Culturas jovens: novos mapas do afeto. Rio de Janeiro: J. Zahar, 2006. p. 192-200.

Recebido em: 27 de fevereiro de 2015 Aceito em: 15 de setembro de 2017 